\title{
Morquio Syndrome in Two Siblings: A Case Report
}

\author{
Malla KK ${ }^{1}$, Malla ${ }^{2}$, Basnet $\mathrm{S}^{3}$, Rao $\mathrm{KS}^{4}$, Tiwari PK ${ }^{5}$, Ghosh $\mathrm{A}^{6}, \mathrm{KC} \mathrm{N}{ }^{7}$ \\ ${ }^{1}$ Dr. Kalpana Malla, Associate Professor, ${ }^{2}$ Dr. Tejesh Malla, Assistant Professor, ${ }^{3}$ Dr. Sahisnuta Basnet, Lecturer, \\ ${ }^{4}$ K.S.Rao, Professor and Head of Department of Paediatrics, ${ }^{5}$ Dr. P.K.Tiwari, Professor and Head of Department of \\ Radiology, ${ }^{6}$ Dr. Arnab Ghosh, Associate Professor, Department of Pathology, ${ }^{7}$ Dr. Namrata KC, Medical Officer. All from \\ Manipal College of Medical Sciences, Pokhara, Nepal.
}

Address for correspondence: Dr. Kalpana Malla, E-mail: kalpana_malla@hotmail.com

\begin{abstract}
Morquio syndrome is a rare inherited autosomal recessive disorder characterized by the accumulation of mucopolysaccharides (glycosaminoglycans) in various body tissues. It is rare cause of dwarfism. Many pediatricians therefore are unlikely to see this case hence may miss the diagnosis due to lack of experience. With this view we report two siblings with this dwarfism highlighting the classical clinical and radiological presentation.
\end{abstract}

Key words: Mucopolysaccharidosis, Morquio syndrome

\section{The Case}

$A^{\text {six }}$ six year old female child was brought to the out atient department of Manipal Teaching Hospital with symptoms of lower respiratory tract infection. On examination she had akward looking facies with frontal bossing and bilateral proptosis (Fig 1)hence was admitted for further evaluation. She was disproportionately short (short trunk and long limbs (Fig 1)), with height $95 \mathrm{~cm}$ (Expected height $114 \mathrm{~cm}$ (Height / age 83\% moderate stunting according to Waterlow classification). She also had other skeletal abnormalities like pectus carinatum, short neck, knock - knees, kyphosis, joint hypermobility, projecting jaw, broad mouth and flat feet. She had a younger brother having similar features. Her parents had a consanguineous marriage. Both parents were normal looking. The parents never thought that their children had any problems as both looked alike and their intelligence and development was age appropriate (Fig 2).Skeletal survey of both siblings revealed features of MPS - X- ray of the skull showed large skull with a J-shaped sella. Atlantoaxial subluxation was seen in radiographs of the cervical spine (Fig 3). Oar-shaped ribs were seen in $A P$ and lateral views of the chest X-ray (Fig 4). Standing AP and lateral views of lower thoracic and lumbar vertebrae revealed flat and irregular vertebral bodies, along with anterior beaking of the vertebral bodies (Fig 5). The pelvic radiograph showed flared ilia with inferior constriction ("wine-glass" shape) (Fig 6). X-ray of knees hand and forearm in AP view showed genu valgus (Fig 7), metaphyseal expansion of long bones, and tapering of the proximal phalanges (Fig 8) respectively. Besides skeletal abnormalities they also had hepatomegaly, Corneal clouding and congenital cataract. On cardiovascular evaluation the sister had mild to moderate mitral regurgitation. Bone marrow biopsy revealed increased foamy histiocytes with large vacuolated cytoplasm which was consistent with the diagnosis of MPS type IV, Morquio syndrome (Fig 9). Due to the unavailability of other investigations like urinary keratine level, Fibroblast culture of a skin biopsy for reduced activity of $\mathrm{N}$-acetyl-galactosamine-6-sulfatesulfatase and genetic study could not be performed.

\section{Discussion}

Morquio syndrome (mucopolysaccharidosis type IV; MPS IV) is a rare mucopolysaccharide storage disease that exists in two forms (Morquio syndromes $A$ and $B$ ) and occurs because of a deficiency of the enzymes $\mathrm{N}$-acetyl-galactosamine-6-sulfatase and beta-galactosidase, respectively ${ }^{1,2}$ It was first described simultaneously by Morquio $^{3}$, a pediatrician in Uruguay and Brailsford ${ }^{4}$, a radiologist in England in year 1929. 


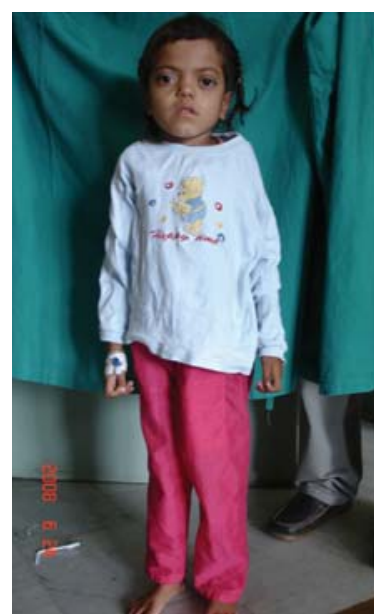

Fig1: Patient having abnormal facies and disproportionate short stature (photographed with permission of mother).

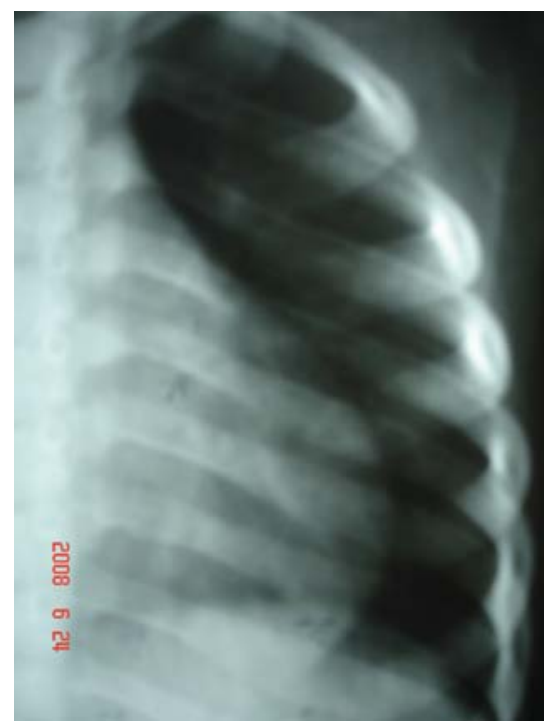

Fig 4: X-Ray of chest (PA view) Showing Oar-shaped ribs of the patient.

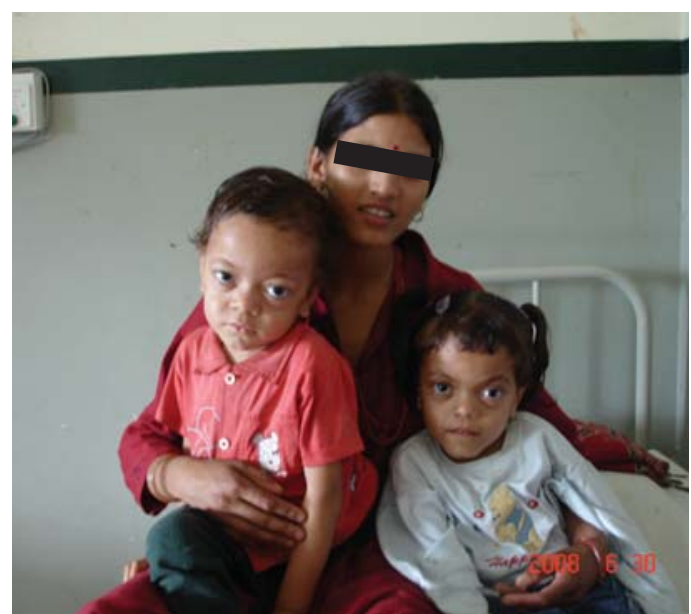

Fig 2: Photograph of Both siblings with mother (with permission).

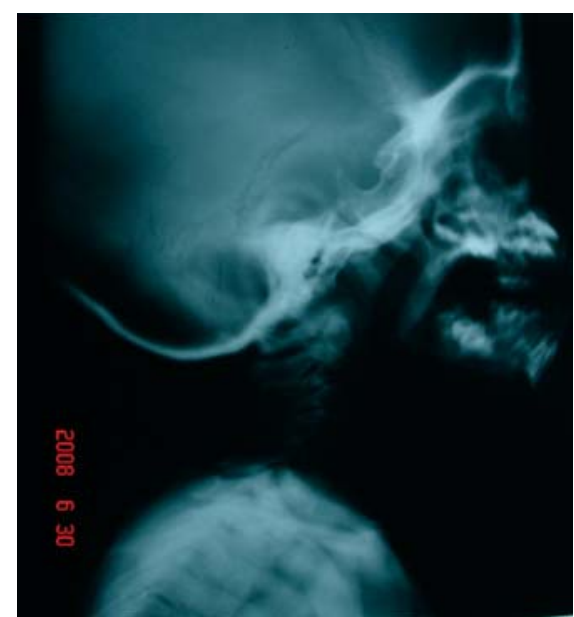

Fig 3: X-Ray of skull (Lateral view) showing large skull with a J-shaped sella of the patient

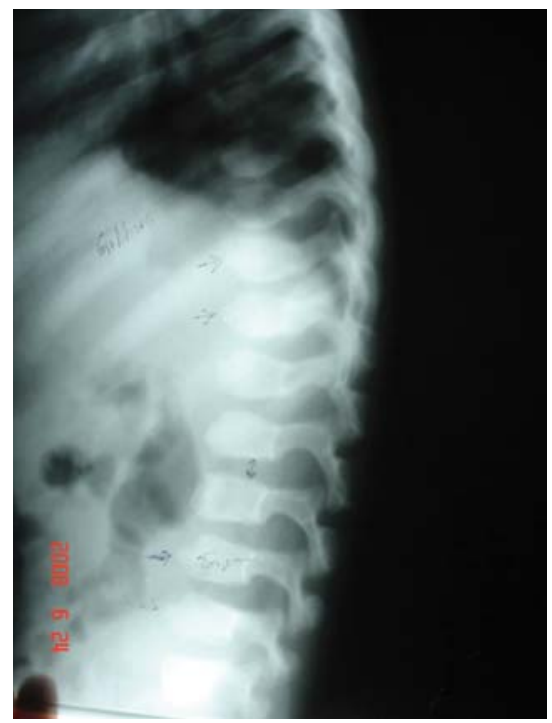

Fig 5: X-ray vertebrae (lateral view) of patient showing flattening and irregularity of the vertebral bodies with anterior beaking.

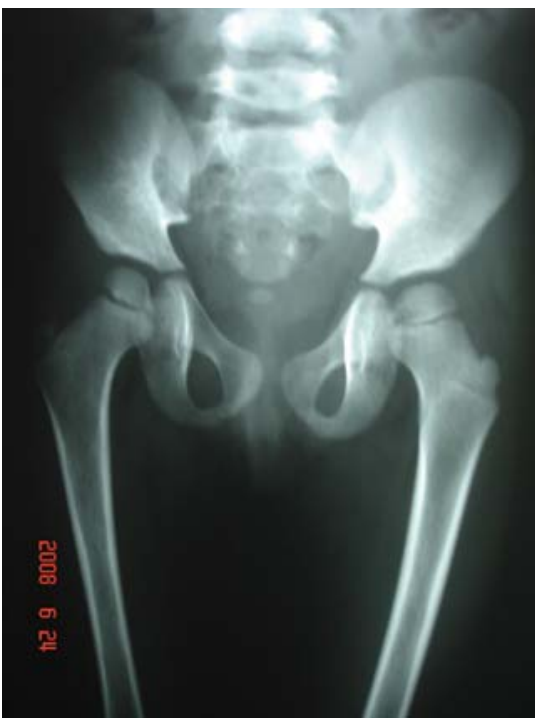

Fig 6: X-Ray pelvis and both femur (AP view) showing "wineglass" shape
The incidence is unknown but estimates have ranged from 1 case per 75,000 people in Northern Ireland to 1 case per 200,000 people in British Columbia ${ }^{2}$. Deficiency of above mentioned enzymes lead to the accumulation of mucopolysaccharides or glycosaminoglycans (GAGs) in the body, giving rise to various symptoms. Dermatan sulfate, heparan sulfate, keratan sulfate (KS), and chondroitin sulfate are the main GAGs in tissues ${ }^{5}$. Clinical features vary depending on the tissue distribution of the affected substrate and the degree of enzyme deficiency. In Morquio syndrome, the GAG which is defective is KS. This defective degradation of KS occurs due to deficiency of either $N$-acetyl-galactosamine-6-sulfatase (GALNS gene) in MPS IVA or beta-galactosidase (GLB1 gene) in MPS IVB ${ }^{5}$. KS is predominantly found in cartilage and cornea and these are the major organs affected in Morquio syndrome. In our case also these were the major organs involved.The metabolism of Heparan and dermatan sulfate which has more generalized tissue distribution is normal in Morquio syndrome.This is the reason why patients with Morquio syndrome does not have mental retardation. Both the siblings in the above case had normal intelligence. Compared to other MPS, Morquio syndrome tend to have greater skeletal manifestations and spine involvement like scoliosis, kyphosis, hyperlordosis and severe gibbus, flaring of the lower ribs as well as platyspondyly, pectus carinatum, 


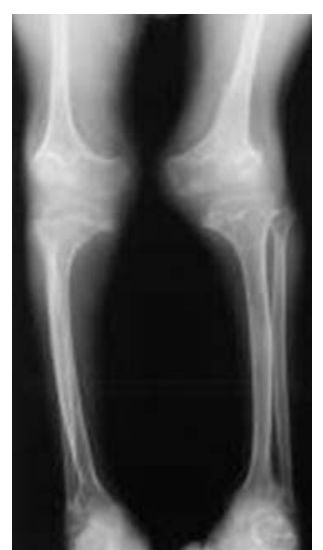

Fig 7: X- Ray both knees and leg (AP view) showing genu valgus in the patient.

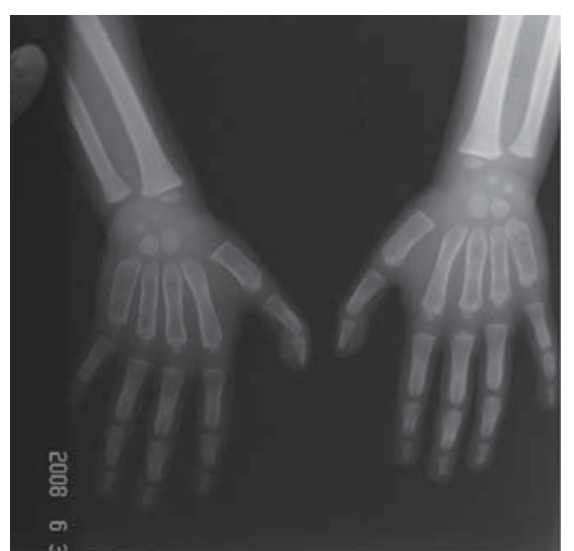

Fig 8: X - Ray both hands (AP view) showing metaphyseal expansion of long bones with cortical thinning, and tapering of the proximal phalanges in the patient. and ligamentous laxity, odontoid hypoplasia, a striking short trunk dwarfism, short neck, flat feet, genu valgus, projecting jaw, broad mouth ${ }^{6,7}$. Additional physical features are hearing defects, carious teeth, growth retardation, hepatomegaly, and aortic and/or mitral regurgitation ${ }^{8,9}$.

All these features were present in our case except for hearing which was normal. No clear clinical differentiation between Morquio syndrome type IVA and IVB exists. The clinical features of MPS IV-B are usually fewer and milder than those associated with MPS IV- $\mathrm{A}^{10}$.With this view possibly our case is Morqio syndrome type IV-B. Patients with Morquio syndrome have a predisposition to pulmonary infection because of progressive truncal deformity and immobility. Earlyonset coronary heart disease and valve thickening (aortic and mitral) with resultant cardiac dysfunction are also described in these patients ${ }^{8}$. Pulmonary infection was observed in our case. Other rare abnormalities include lens opacities, retinopathy, optic atrophy, and pseudoexophthalmos ${ }^{11}$. Lens opacities and pseudoexophthalmos was present in both our cases.

Imaging findings in Morquio is very helpful for diagnosis.To describe the skeletal findings Husler coined the term dysostosismultiplex ${ }^{12}$. The radiological features as described above in our case are consistent with dysostosis multiplex. The diagnosis is confirmed by direct enzymatic assay in leukocytes or fibroblasts ${ }^{13}$. As this facility was not available in our setup we could not perform this test. The Histological finding shows engorged unmetabolized GAG in lysosomes. These appear as vacuoles or inclusion bodies in cells such as lymphocytes, hepatocytes, corneal epithelium, and neurons ${ }^{14}$.

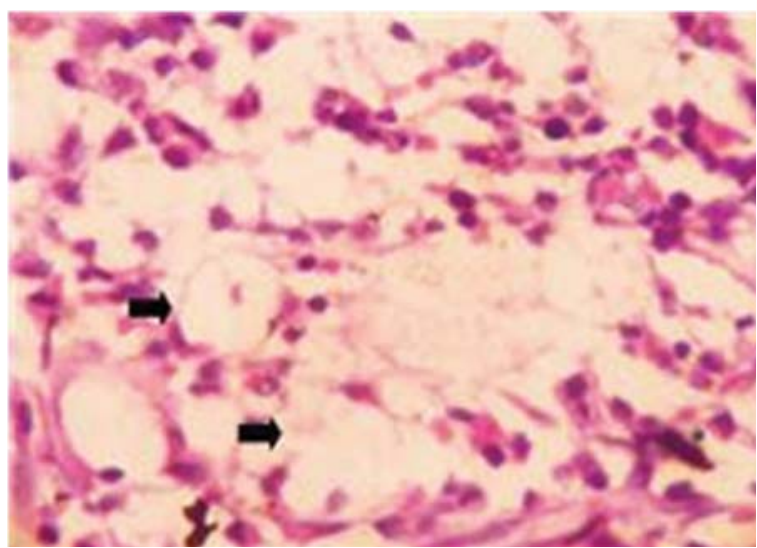

Fig 9: Photomicrograph (H\&E, 1000x) of bone marrow of patient showing histiocytes (arrows) with large vacuolated cytoplasm.

Treatment is only palliative for Morquio syndrome. Potential strategies - which are currently at different levels of development, include enzyme replacement, gene therapy, and allogenic bone marrow transplantation in which engrafted cells provide the normal enzyme ${ }^{15}$.

\section{Conclusion}

This gives a guideline to suspect diagnosis of mucopolsaccharidosis. We strongly recommend the importance of performing careful clinical examination and proper investigations for such cases.

\section{Acknowledgement}

We acknowledge the co-operaton of the mother of two siblings and thank her to have given us permission to publish this case.

\section{References}

1. Beck M, Braun S, Coerdt W, Merz E, Young E, Sewell AC. Fetal presentation of Morquio disease type A. Prenatal Diag 1992;12:1019-1029.

2. Beck, M.; Glossl, J.; Grubisic, A.; Spranger, J. Heterogeneity of Morquio disease. Clin Genet 1986;29:325-331.

3. Morquio, L. :Sur une forme de dystrophie osseuse familiale. Bull. Soc. Pediat Paris 1929;27:145-152.

4. Brailsford J F. Chondro-osteo-dystrophy: roentgenographic and clinical features of child with dislocation of vertebrae. Am J Surg 1929;7:404410.

5. Singh J, DiFerrante NM, Niebes P,Tavella D. $\mathrm{N}$-acetylgalactosamine-6-sulfate sulfatase in man: 
absence of the enzyme in Morquio disease. J Clin Invest 1976;57:1036-1040.

6. Holzgreve W, Grobe $\mathrm{H}$, von Figura K, Kresse $\mathrm{H}$, Beck $H$, Mattei J F. Morquio syndrome: clinical findings in 11 patients with MPS IVA and 2 patients with MPS IVB. Hum. Genet 1981;57:360-365.

7. Montano AM, Tomatsu S, Gottesman GS, Smith M, Orii T. International Morquio A Registry: clinical manifestation and natural course of Morquio $A$ disease. J Inherit Metab Dis 2007;30(2):165-74.

8. Factor SM, Biempica L, Goldfischer S. Coronary intimal sclerosis in Morquio"s syndrome. Virchows Arch A Pathol Anat Histol 1978;379(1):1-10.

9. Riedner E D, Levin LS. Hearing patterns in Morquio's syndrome (mucopolysaccharidosis IV). Arch. Otolaryng 1977;103:518-520.

10. Beck M, Glossl J, Grubisic A,Spranger J. Heterogeneity of Morquio disease. Clin Genet 1986;29: 25-331.
11. Ashworth JL, Biswas S, Wraith E, Lloyd IC. Mucopolysaccharidoses and the eye. Surv Ophthalmol 2006;51(1):1-17.

12. Langer LO, Jr, Carey LS. The roentgenographic features of the KS mucopolysaccharidosis of Morquio (Morquio-Brailsford's disease). Am. J. Roentgen 1966;97:1-20.

13. Yuen, M.; Fensom, A. H. : Diagnosis of classical Morquio's disease: $\mathrm{N}$ acetylgalactosamine 6-sulphate sulphatase activity in cultured fibroblasts, leukocytes, amniotic cells and chorionic villi. J Inherit Metab Dis 1985;8:80-86.

14. Forfar \& Arneil's. Lysosomal Storage Disorders. Textbook of Pediatrics $-.5^{\text {th }}$ ed. Campbell A.G.M \& McIntosh N, BPC Wheatons Ltd; Exeter; 1998. $1156-1162$.

15. Tomatsu S, Montano AM, Ohashi A, et al. Enzyme replacement therapy in a murine model of Morquio A syndrome. Hum Mol Genet 2008;17(6):815-24.

\section{How to cite this article?}

Malla KK, Malla T, Basnet S, Rao KS, Tiwari PK, Ghosh A, KC N. Morquio Syndrome in Two Siblings: A Case Report. J Nepal Paedtr Soc 2011;31(1):68-71. 